\title{
SCREENING OF SAFFLOWER GERMPLASM AGAINST ALTERNARIA LEAF SPOT
}

\author{
H.N. Aiwale*, D.R. Murumkar. S.V. Khadtare, L.N. Tagad and K.C. Ombase \\ AICRP on Safflower, Krishak Bhawan, ZARS, 97, Raviwar Peth, Solapur
}

\begin{abstract}
:
The present study was made to evaluate safflower germplasm accessions for resistance against Alternaria leaf spot. Natural disease screening was carried out during rabi 2018-19 at AICRP on Safflower, Zonal Agricultural Research Station, Solapur by growing a total of 46 safflower test entries. Based on intensity of disease,23entries shown tolerant reaction with the disease intensity of less than 40 per cent and remaining entries along with checks were classified either under susceptible or highly susceptible group. This study further substantiates the lack of high and stable sources of resistance to alternaria leaf spots among the germplasms in safflower.
\end{abstract}

Key words: - Safflower, germplasm, Alternaria leaf spot, resistance.

\section{INTRODUCTION:}

Safflower is an important rabi oilseed crop primarily grown for its much-valued edible oil having world-wide acceptability for its health benefits especially to heart patients. In India, it is cultivated in an area of 1.5 lakh ha with a production of 1.13 lakh tons giving a productivity of $726 \mathrm{~kg} / \mathrm{ha}$. Maharashtra and Karnataka are the first and second with reference to area and production, respectively whereas, productivity is highest in West Bengal (1000 kg/ha) followed by Bihar (805 $\mathrm{kg} / \mathrm{ha})$ and Karnataka $(719 \mathrm{~kg} / \mathrm{ha})$. There are numbers of safflower varieties under cultivation in different agroclimatic region in India. Still the area under cultivation decreases day by day. Number of factors is responsible for decreasing area. Crop damage due to pest and disease is one of the major constraints. Among these two, the leaf spot disease caused by Alternaria carthami is a serious problem especially when wet cloudy weather prevails continuously for more than a week during flowering period. In India, the disease is reported to cause $25-60 \%$ yield loss (Singh and Prasad, 2005) and some times as high as $80-90 \%$, when the disease appears at early stage of crop growth (Krishna Prasad, 1988). Breeding safflower for disease resistance is the most economical and convenient method for controlling major diseases. Mundel and Huang (2003) described in detail how to control major diseases of safflower by breeding and using cultural practices. Though, germplasm lines or cultivars showing partial or full resistance to some of the major diseases have been identified, the availability of genetic resistance is rare. To overcome this problem, present study was carried out to find out germplasm accession for resistant to Alternaria disease.

The leaf spot disease caused by Alternaria carthami Chowdhary is a major destructive disease of safflower (Carthamus tinctorius L.) grown in India. The disease is endemic in most of the safflower growing areas 
of Maharashtra, Karnataka and Andhra Pradesh. The pathogen infects leaves, stem, head, seed and causes severe seed yield losses and deterioration in the quality of the seed. Under severe infection, the disease has been reported to cause 50 per cent loss in seed yield (Indi et al., 1986). The weather conditions play a predominant role in determining the cause and severity of epidemics of the Alternaria leaf spot disease. Hence, an attempt was made to study the impact of different weather parameters viz., rainfall, temperature and relative humidity on infection and further development of Alternaria leaf spot on safflower.

\section{MATERIALS AND METHODS:}

The experiment was carried out at AICRP on Safflower, Solapur during rabi 2018- 19. The experimental material for the present study comprised of 46 safflower germplasm accessions obtained from the Directorate of Oilseeds Research, Hyderabad. Disease screening for Alternaria was done under field conditions. The 46 genotypes were screened in natural conditions in a single row of $4 \mathrm{~m}$ length replicated twice having a closer spacing of $30 \times 15 \mathrm{~cm}$ to favour disease development using HUS-305 as a tolerant check, Manjira as susceptible check, A-1 as national check and SSF-748 as local check. The Alternaria leaf spot disease of safflower is favoured by temperature around $25-30^{\circ} \mathrm{C}$ and relative humidity above $80 \%$. Considering these predisposing factors, a technique of early sowing during second fortnight of August was followed to create natural epiphytotic of the disease. The early sown crops succumb to early infection of by the disease and get exposed to the congenial conditions for a longer period due to intermittent rains and high humidity during September and October offering a severe disease pressure. The conidial suspension was sprayed on the crop frequently in the evening hours. On the next day the crop was sprayed with water to provide favourable humidity for infection. Five randomly selected plants from each plot were scored for the disease reaction at its peak incidence at 15 days interval using 1-9 scale (Anonymous 2006). The percent disease index (PDI) values were calculated by the formula suggested by Mayee and Datar (1986)

\section{RESULTS AND DISCUSSION:}

The occurrence of natural epiphytotic of Alternaria significantly reduce seed yield in safflower. It is one trait which requires attention especially in the current scenario of climatic uncertainty. The results in respect of reaction of safflower genotypes to Alternaria leaf spot are depicted in Table No.1 and 2. Out of 46 genotypes screened in the present investigation 23 germplasm accessions were found tolerant for the disease viz., SAF-P1606, SAF-P-1608, SAF-P-1701, SAF-P-1702, SAF-P-1706, SSF-1660, SSF-1801, PBNS-137, PBNS-138, PBNS-154, ISF-1749-1-5-2016, ISF-1703-2-1-2016, ISF-1749-1-2-2016, SAFP-1507, SAF-P-1603, SAF-P-1608, SAF-1401, SAF-1556, SAF-1659, SAF-1685, SAF-1689, SAF-1711, SAF-1738. Twenty three accessions showed susceptible reaction with grade 7 viz., SSF-1607, SSF-1656, SSF-1673, SSF-1677, PBNS-130, PBNS-152, 3350-8-11-2016, 33502-4-2016, 3350-3-4-2016, ISF-116, ISF-4, SAF-P-1601, SAF-1517, SAF-1617, SAF-1630, SAF-1693, SAF-1701, SAF-1710, SAF1717,GMU-2757, PBNS-170, PBNS-171, PBNS-172. No resistance to Alternaria disease was found in the germplasm screened, indicating lack of tolerance or resistance in the cultivated genotypes especially under high disease pressure conditions. The present study further substantiates the lack of high and stable sources of resistance to alternaria leaf 
spots among the cultivated genotypes of safflower. It is already confirmed by earlier studies of Madhavi et al. (2005), Prasad and Anjani (2008), Gud et al. (2008), Murumkar et al. (2009) that there is no resistance available in the cultivated genotypes of safflower.

\section{REFERENCES:}

Gud, M. A., D. R. Murumkar, S. K. Shinde and J. R. Kadam (2008). Correlation of weather parameters with development of leaf spot of safflower caused by Alternaria carthami. 7th Intl. Safflower Conf., Wagga Wagga, Australia.

Indi, D.V., G. M. Lukade and P. S. Patil.1986. Influence of Alternaria leaf spot (A.carthami Chowdhari) on growth and yield of safflower. Curr. Res. Rept., 2(1):137-139.

Krishna Prasad, N. V. (1988). Studies on the Alternaria leaf blight of safflower (Carthamus tinctorius L.). Ph.D. Thesis, Varanasi: Benaras Hindu University. P. 168.

Madhavi, K. J., M. Sujatha, R. D. Reddy and S. Chandra Rao (2005). Culture characteristics and histological changes in leaf tissues of cultivated and wild sunflowers infected with
Alternaria helianthi. Helia, 28, 43 : 112.

Mayee, C. D. and V. V. Datar (1986). Diseases of safflower, Phytopathometry, a technical bulletin published by

Marathwada Agricultural University, Parbhani (MS), India, pp. 100-104.

Mundel, H. H. and H. C. Huang (2003). Control of major diseases of safflower by breeding for resistance and using cultural practices. Adv. P1. Disease Manag., 21 : 562-568.

Murumkar, D. R., D. V. Indi, V. B. Akashe, Patil and Gud (2009). Multiple resistance sources against major diseases and pests of safflower. J. Oilseeds Rec., 26(2) : 175-176

Prasad, R. and K. Anjani (2008). Sources of resitance $t$ Alternaria leaf spot among Carthamus wild species, 7th Intl. Safflower Conf., Wagga Wagga Australia.

Singh,. and R. D. Prasad (2005). Integrated managemet of pests and diseases in safflower. Directorate of Oilseeds Research, Hyderabad, India, pp 49. www.indiastat.com 2014. View publication stats

Table 2. Disease reaction of 46 safflower accessions with 4 checks to Alternaria leaf spot disease at AICRP on Safflower, Solapur under natural field conditions during Rabi 2018-19.

\begin{tabular}{|l|l|l|l|l|l|}
\hline Sr. No. & Entry & Disease severity (\%) & \multicolumn{2}{l|}{ Seed yield (g/4 m row) } \\
\cline { 3 - 6 } & & Protected & Unprotected & Protected & Unprotected \\
\hline 1 & SAF-P-1606 & 25.6 & 33.3 & 136 & 120 \\
\hline 2 & SAF-P-1608 & 26.7 & 33.3 & 148 & 124 \\
\hline 3 & SAF-P-1701 & 26.7 & 32.2 & 148 & 130 \\
\hline 4 & SAF-P-1702 & 25.6 & 32.2 & 134 & 128 \\
\hline 5 & SAF-P-1706 & 24.1 & 31.1 & 140 & 128 \\
\hline 6 & SSF-1607 & 41.1 & 82.2 & 192 & 148 \\
\hline 7 & SSF-1656 & 40.0 & 84.4 & 180 & 151 \\
\hline 8 & SSF-1660 & 23.1 & 34.4 & 154 & 140 \\
\hline 9 & SSF-1673 & 38.9 & 76.7 & 158 & 144 \\
\hline 10 & SSF-1677 & 38.9 & 81.1 & 193 & 151 \\
\hline 11 & SSF-1801 & 24.4 & 31.1 & 178 & 158 \\
\hline
\end{tabular}


I J R B A T, Issue (VIII), Vol. III, Sept 2020: 113-117

\begin{tabular}{|c|c|c|c|c|c|}
\hline 12 & PBNS-137 & 27.8 & 32.2 & 142 & 130 \\
\hline 13 & PBNS-138 & 24.3 & 34.4 & 178 & 158 \\
\hline 14 & PBNS-130 & 41.1 & 82.2 & 192 & 148 \\
\hline 15 & PBNS-152 & 40.0 & 84.4 & 180 & 151 \\
\hline 16 & PBNS-154 & 25.7 & 38.8 & 146 & 132 \\
\hline 17 & ISF-1749-1-5-2016 & 23.6 & 31.1 & 149 & 138 \\
\hline 18 & $3350-8-11-2016$ & 41.1 & 82.2 & 192 & 148 \\
\hline 19 & $3350-2-4-2016$ & 40.0 & 84.4 & 180 & 151 \\
\hline 20 & ISF-1703-2-1-2016 & 25.1 & 32.2 & 148 & 138 \\
\hline 21 & $3350-3-4-2016$ & 38.9 & 81.1 & 136 & 101 \\
\hline 22 & ISF-1749-1-2-2016 & 23.8 & 33.3 & 182 & 164 \\
\hline 23 & ISF-116 & 41.1 & 82.2 & 192 & 148 \\
\hline 24 & ISF-4 & 40.0 & 84.4 & 180 & 151 \\
\hline 25 & SAF-P-1507 & 23.6 & 31.1 & 142 & 136 \\
\hline 26 & SAF-P-1601 & 38.9 & 81.1 & 193 & 151 \\
\hline 27 & SAF-P-1603 & 24.1 & 32.2 & 144 & 120 \\
\hline 28 & SAF-P-1608 & 26.7 & 33.3 & 164 & 152 \\
\hline 29 & SAF-1401 & 24.3 & 32.2 & 148 & 122 \\
\hline 30 & SAF-1517 & 36.7 & 80.0 & 156 & 105 \\
\hline 31 & SAF-1556 & 27.1 & 34.4 & 142 & 124 \\
\hline 32 & SAF-1617 & 38.9 & 81.1 & 193 & 151 \\
\hline 33 & SAF-1630 & 41.1 & 82.2 & 192 & 148 \\
\hline 34 & SAF-1659 & 24.4 & 33.3 & 160 & 146 \\
\hline 35 & SAF-1685 & 27.8 & 31.1 & 148 & 138 \\
\hline 36 & SAF-1689 & 24.3 & 32.2 & 148 & 122 \\
\hline 37 & SAF-1693 & 36.7 & 80.0 & 156 & 105 \\
\hline 38 & SAF-1701 & 37.8 & 84.4 & 147 & 109 \\
\hline 39 & SAF-1710 & 37.8 & 81.1 & 149 & 115 \\
\hline 40 & SAF-1711 & 24.3 & 32.2 & 148 & 122 \\
\hline 41 & SAF-1717 & 36.7 & 80.0 & 156 & 105 \\
\hline 42 & SAF-1738 & 26.7 & 33.3 & 198 & 162 \\
\hline 43 & GMU-2757 & 38.9 & 76.7 & 158 & 144 \\
\hline 44 & PBNS-170 & 38.9 & 81.1 & 193 & 151 \\
\hline 45 & PBNS-171 & 41.1 & 82.2 & 192 & 148 \\
\hline 46 & PBNS-172 & 40.0 & 84.4 & 180 & 151 \\
\hline 47 & Manjira (SC) & 62.2 & 96.7 & 110 & 84 \\
\hline 48 & HUS-305(TC) & 17.8 & 23.3 & 142 & 126 \\
\hline 49 & A-1 (NC) & 38.8 & 64.4 & 202 & 165 \\
\hline 50 & SSF-748 (LC) & 36.1 & 56.1 & 210 & 172 \\
\hline
\end{tabular}


Table 2. Screening of safflower genotypes against Alternaria leaf spot under natural field conditions

\begin{tabular}{|c|c|c|c|}
\hline $\begin{array}{l}\text { Disease } \\
\text { rating }\end{array}$ & Area affected & Reaction & Name of genotype \\
\hline 0 & No symptoms & Immune & Nil \\
\hline 1 & $<1 \%$ & Resistant & Nil \\
\hline 3 & $1-10 \%$ & Moderately Resistant & Nil \\
\hline 5 & $11-25 \%$ & Tolerant & $\begin{array}{l}\text { SAF-P-1606, SAF-P-1608, SAF-P-1701, SAF-P- } \\
\text { 1702, SAF-P-1706, SSF-1660, SSF-1801, PBNS- } \\
\text { 137, PBNS-138, PBNS-154, ISF-1749-1-5-2016, } \\
\text { ISF-1703-2-1-2016, ISF-1749-1-2-2016, SAF-P- } \\
\text { 1507, SAF-P-1603, SAF-P-1608, SAF-1401, SAF- } \\
\text { 1556, SAF-1659, SAF-1685, SAF-1689, SAF- } \\
1711, \text { SAF-1738 }\end{array}$ \\
\hline 7 & $26-50 \%$ & Susceptible & $\begin{array}{l}\text { SSF-1607, SSF-1656, SSF-1673, SSF-1677, } \\
\text { PBNS-130, PBNS-152, 3350-8-11-2016, 3350-2- } \\
\text { 4-2016, 3350-3-4-2016, ISF-116, ISF-4, SAF-P- } \\
\text { 1601, SAF-1517, SAF-1617, SAF-1630, SAF- } \\
\text { 1693, SAF-1701, SAF-1710, SAF-1717, GMU- } \\
2757, \text { PBNS-170, PBNS-171, PBNS-172 }\end{array}$ \\
\hline 9 & Above $51 \%$ & Highly susceptible & Nil \\
\hline
\end{tabular}

